\title{
The analysis of friction properties after laser texturizing of the silicon carbide surface layer
}

\author{
Norbert Radek ${ }^{1, *}$, Agnieszka Szczotok $^{3}$, and Renata Dwornicka ${ }^{3}$ \\ ${ }^{1}$ Kielce University of Technology, Faculty of Mechatronics and Mechanical Engineering, Al. 1000- \\ lecia Panstwa Polskiego 7, 25-314 Kielce, Poland \\ ${ }^{2}$ Silesian University of Technology, Institute of Materials Science, str. Krasinskiego 8, 40-019 \\ Katowice, Poland \\ ${ }^{3}$ Cracow University of Technology, Faculty of Mechanical Engineering, Al. Jana Pawła II 37, 31-864 \\ Cracow, Poland
}

\begin{abstract}
The modification of the surface properties is a desired technological procedure. One of the possible method is the electro-spark deposition (ESD). Unfortunately, ESD process produces a surface with high roughness. The laser beam machining (LBM) has been involved to lower roughness of the coating made by ESD. The elements coated by ESD have been tested to determine tribological properties and they were compared before and after LBM. To achieve high reliability of the results, the test has been conducted in accordance with design of experiments methodology and the results which were obtained have been processed by a statistical analysis. The description of such an experiment performed for a silicon carbide $\mathrm{SiC}$ coating, the obtained results and the conclusions are included in this paper.
\end{abstract}

\section{Introduction}

During tribological investigations, it was found that employing heterogeneous surfaces models into boundary interaction of solid surfaces could make significant improvement [1]. Surfaces described as heterogeneous consist of areas, which are different one from another in geometrical, physicomechanical or physicochemical properties. The heterogeneity of surfaces is frequently due to the application of more than one technology, and can be constituted by $[2,3]$ :

- shaped surface features such as grooves, pits or channels resulting from milling, eroding, etching, laser-beam forming, etc.,

- areas with different physicochemical and physicomechanical properties, e.g. areas with varying hardness and mechanical strength accomplished by local surfacing or selective surface hardening (e.g. electron-beam machining, laser-beam forming or thermochemical treatment),

- areas with diversified surface microgeometry, e.g. areas eroded at the points of focus (laser treatment or electro-spark deposition), or areas with formed surface

\footnotetext{
*Corresponding author: norrad@tu.kielce.pl
} 
microgeometry, for instance, in terms of desired microroughness directivity or load capacity (LBM and ESD technologies).

Heterogeneous surfaces can be obtained by different methods. The laser treatment of electro-spark deposited coatings being one of them.

The first publication on surface texturing appeared in Germany in 1993 [4]. It discussed the use of an excimer laser to texture elements of a magnetic memory disk drive with the aim of reducing friction at the start. Further experiments in this area involved texturing surfaces of punches applied to plastic forming. It was found that the process caused a $169 \%$ increase in the punch service life.

The current studies focus on the influence of texturing on the performance of various friction systems in internal combustion engines, e.g. precision bearing systems. Texturing is used to improve heat removal, vaporization, wettability, biological functions, absorptivity, etc.

In the considered experiment, two parameters controlling LBM process were investigated: the cavity diameter and the level of blackening. The average friction coefficient, being the investigated outcome, was determined on the tribological tester. The experiment was conducted according to response surface methodology (RSM) [5, 6], which is a part of the design of experiments (DoE) methodology [7, 8]. The appropriate RSM model was identified and accompanying plots were made.

\section{Texturing methodology}

Laser surface texturing is one of the most common and promising methods of surface roughening. Categorized as a metal removal process, laser texturing is usually performed at a power density of $10^{6} \div 10^{9} \mathrm{~W} / \mathrm{cm}^{2}$. At present, it accounts for about $2 \%$ of all laser-based material processing processes used in the world. In laser surface texturing, a pulsed laser beam is focused on a material to melt a hole. The hole depth is dependent mainly on the power density and the pulse duration. The drilling debris is removed from a hole being drilled using compressed air or another inert gas.

The tests were conducted for SiC rings (certificate of material excellence) with the following dimensions: an outer diameter $d_{o}$ of $35.3 \mathrm{~mm}$, an inner diameter $d_{i}$ of $25.1 \mathrm{~mm}$, and a height $\mathrm{h}$ of $7 \mathrm{~mm}$. The texturing was performed usingan ESI $5200 \mathrm{Nd}$ :YAG laser (pulse mode). A view of the ESI 5200 laser $\mu$ via drill used in the tests is presented in Fig. 1. The wavelength $\lambda=355 \mathrm{~nm}$ (the laser uses radiation at the third harmonic frequency).

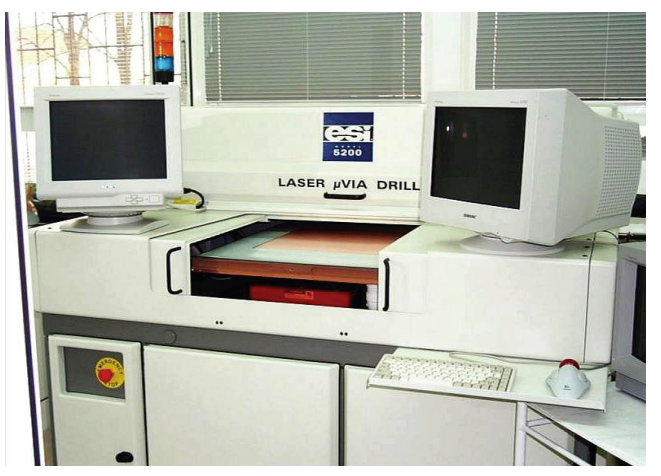

Fig. 1. A view of the ESI 5200 laser $\mu$ via drill.

The parameters of the laser surface texturing process were determined basing on the experimental results: the laser spot diameter $d=0.78 \div 150 \mu \mathrm{m}$; the laser power 
$P=0.37 \div 0.4 \mathrm{~W}$; the laser beam velocity $v=15.7 \div 23.56 \mathrm{~mm} / \mathrm{s}$; the distance from the focus $\Delta f=0 \mathrm{~mm}$; the repetition frequency $f=6400 \mathrm{~Hz}$.

The process of texturing was performed in two stages (two steps). In the first step, holes with a pre-determined diameter were drilled along a spiral path. In the second step, the drilling debris was removed from each pore, with the number and frequency of pulses being strictly defined.

\section{Materials and methods}

The samples of material were processed by a laser erosion and then analyzed visually and geometrically. Surfaces texturized by a laser beam were investigated to achieve the knowledge of technological parameters at different loads of a friction pair. The research was conducted as a designed experiment [9-13] to maximize an information amount about performance parameters at the fixed number of experiment.

Rings (Fig. 2) with external diameter of $35.3 \mathrm{~mm}$, internal diameter of $25.1 \mathrm{~mm}$ and thickness of $7 \mathrm{~mm}$ served as the tested samples (discs). The material of discs was sintered $\mathrm{SiC}$. These were original, commercially available rings for front sealing. The texture was made on rings in accordance to the design of experiment.

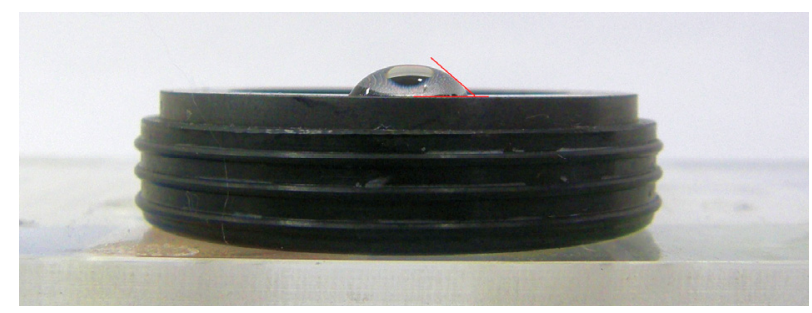

Fig. 2. The investigated ring (during a wettability test).

The effects of a laser induced erosion were investigated visually by scanning microscope Joel JSM-5400. The images was obtained at the magnitude 100x and 500x. Geometrical properties were investigated according to code ISO 25178 using the profilometer Hobson Form Talysurf 120L.

The tribological tester T-01M was used for measurements. The measured outcome was a coefficient of a friction, while the controlled factors were an average diameter of cavities and level of blackening. A typical stem of a tester was replicated with a specifically cut bearing ball (diameter of $6.3 \mathrm{~mm}$ ). Such a circle-shaped cut had a diameter of $4.5 \mathrm{~mm}$. Such a friction pair had a distributed contact with the possibility of self-adjusting. A full range of tester parameters was used sequentially: rotation varied from $100 \mathrm{rpm}$ to $700 \mathrm{rpm}$; a normal load of the friction pair varied from $4.9 \mathrm{~N}$ to $39.2 \mathrm{~N}$.

\section{Experimental Design}

The investigated LBM process was recognized as an object with two controlled factors and one measured quantitative outcome. The average diameter of cavities and the level of a blackening were assumed as input factors. The average coefficient of friction was assumed as an outcome. Due to the fact that both input factors were quantitative the response surface methodology appeared to be the most appropriate.

The average coefficient of friction being the outcome had the range of variation limited to only positive values. Such limitation requires a special treatment during regression 
analysis because potential negative predictions have no physical sense, so the dataset of measured values was transformed into logarithms of these values [14].

The response surface methodology was adopted to identify an appropriate model: the full-quadratic with additional two-way third-order interactions combined with the central composite design for two input factors. The center treatment was replicated five times to estimate a pure error (Tab.1).

The statistical analysis followed a typical approach: the analysis of effects, the analysis of variance (ANOVA), the analysis of standardized effects, the possible correction of a model terms set, a test of normality for residues and, finally, prognostic plots: the contour and 3D. The calculations have been provided in Statsoft STATISTICA software system.

Table 1. Approved design of the experiment.

\begin{tabular}{|c|c|c|}
\hline $\begin{array}{c}\text { Treatment } \\
\text { Number }\end{array}$ & $\begin{array}{c}\text { Diameter of cavity, } \\
\mathbf{A}, \boldsymbol{\mu} \mathbf{m}\end{array}$ & $\begin{array}{c}\text { Level of blackening, } \\
\mathbf{B}, \boldsymbol{\%}\end{array}$ \\
\hline 1 & 78 & 18 \\
\hline 2 & 134 & 18 \\
\hline 3 & 78 & 42 \\
\hline 4 & 134 & 42 \\
\hline 5 & 70 & 27 \\
\hline 6 & 150 & 27 \\
\hline 7 & 102 & 15 \\
\hline 8 & 102 & 50 \\
\hline $9 \ldots 13$ & 102 & 27 \\
\hline
\end{tabular}

\section{Results and discussion}

As an effect of the energy impact the grid of cavities in the shape of a crater (Fig. 3) have appeared. After treatment by means of lapping and superfinishing, flat and hard areas were obtained to transfer normal loads. Neighboring cavities generate hydrodynamic forces during liquid lubrication. Such surfaces may be used among others in sliding friction pairs $[7,8]$. The raw data are presented in 3D scatter plot (Fig. 4). The distribution of datapoints suggests the possibility of the existence of a strong non-linearity.

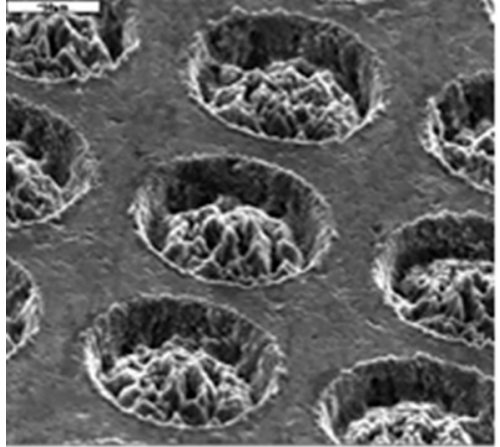

Fig. 3. Texturized surface (magnification of $\mathrm{x} 500$ ).

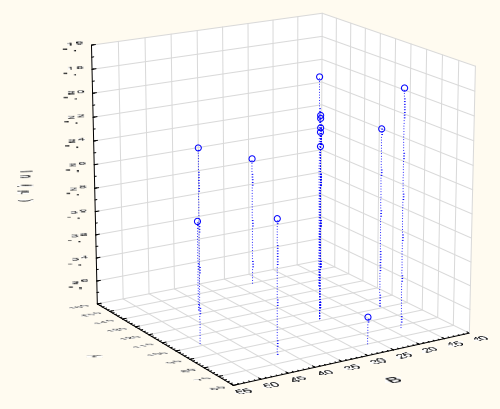

Fig. 4. The 3D scatter plot of raw data. 
Statistical analysis of the obtained data revealed that classic polynomial models did not fit in any way. The deeper analysis of the 3D scatter (Fig. 4) plot suggested that outcome value associated with treatment 5 is a source of the problem. It probably was the outlier. After removing this value from the dataset, the linear model fitted well. Finally, the obtained linear model is as following:

$$
\ln (\mu)=-1.03-7.03 \cdot 10^{-3} \cdot \mathrm{A}-1.79 \cdot 10^{-2} \cdot \mathrm{B}
$$

or in explicite form:

$$
\mu=\exp \left(-1.03-7.03 \cdot 10^{-3} \cdot \mathrm{A}-1.79 \cdot 10^{-2} \cdot \mathrm{B}\right)
$$

The descriptive statistics of the fitted model are presented in Table 2.

Table 2. Approved design of the experiment.

\begin{tabular}{|c|c|c|c|c|c|c|}
\hline \multirow{2}{*}{ Term } & \multirow{2}{*}{ Coefficient } & SE & $\mathbf{t}$ & $\mathbf{p}-$ Value & \multicolumn{2}{|c|}{ Confidence interval } \\
\cline { 5 - 7 } & & & & & $\mathbf{- 9 5 \%}$ & $\mathbf{+ 9 5 \%}$ \\
\hline const & -1.03 & 0.18 & -5.79 & 0.004 & -1.52 & -0.54 \\
\hline A & -0.0070 & 0.0014 & -4.96 & 0.008 & -0.0110 & -0.0031 \\
\hline B & -0.0180 & 0.0029 & -6.21 & 0.003 & -0.0260 & -0.0099 \\
\hline
\end{tabular}

The residuals were tested for a conformity of the normality by Shapiro-Wilk test and $\mathrm{p}$-Value $=0.72$ was obtained. This means that the model is consistent with the assumption of errors normality. The model was visualized by a contour plot (Fig. 5) and 3D response surface (Fig. 6).

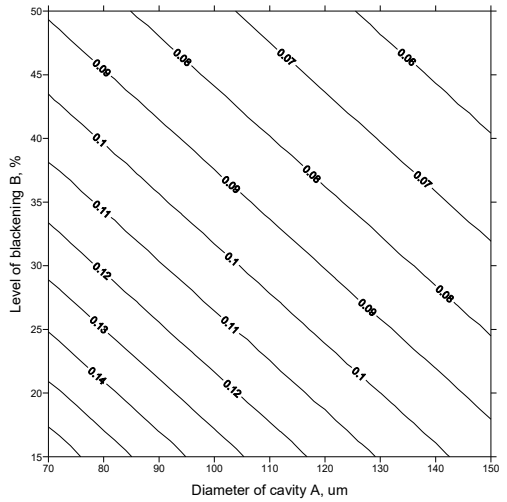

Fig. 5. Contour map of the identified model.

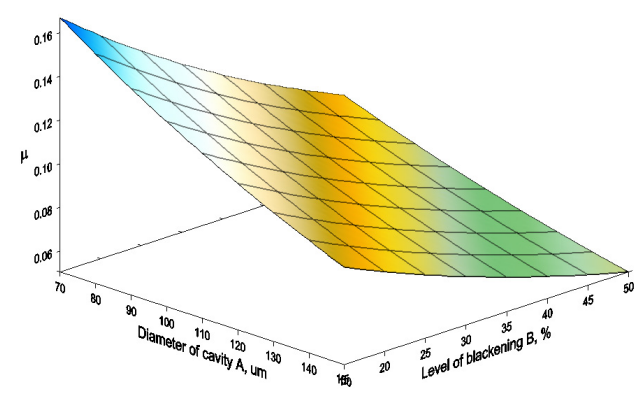

Fig. 6. Response surface plot for the identified model.

\section{Conclusion}

The identified model allows for the combination of such values of a cavity diameter and the level of blackening so that the designer's needs concerning the coefficient of friction may be satisfied. However, due to the lack of a physically based predicting formula, the obtained model may be utilized only locally and any extrapolation is not allowed. In further investigations, it seems it to be worth to employ the techniques of microstructures analysis [15-28], especially with the multivariate analysis [29-31]. Problems with the stability and 
repeatability of the technology process, encountered during the work, have shown the need to apply a quality management system [32-35] in the future research.

\section{References}

1. B. Antoszewski, Influence of laser and plasma modification on surface properties of sliding and rubbing components (Kielce University of Technology, Kielce, 1999)

2. G. Gyk, I. Etsion, Wear, 216, 792 (2006)

3. Y. Wan, X. Dang-Sheng, J. of Mater. Proc. Tech., 197, 96 (2008)

4. J. Arnold, G. Muller, H. Schneider, H.K. Muller, H. Hugel, Laser und Optoelektronik, 25, 12 (1993)

5. G.E.P. Box, N.R. Draper, Empirical Model-Building and Response Surface (John Wiley \& Sons, Hoboken, 1987)

6. R.H. Myers, D.C. Montgomery, Response Surface Methodology. Process and Product Optimization Using Designed Experiments (John Wiley \& Sons, Hoboken, 1995)

7. D.C. Montgomery, Design and Analysis of Experiments (John Wiley \& Sons, Inc., Hoboken, 2008)

8. O. Kempthorne, K. Hinkelmann, Design and Analysis of Experiments.Vol.1. Introduction to experimental design (John Wiley \& Sons, Inc., Hoboken, 1994)

9. B. Antoszewski, Prz. Elektrotechniczny, 87(7), 6 (2011)

10. J. Pietraszek, Proc. $6^{\text {th }}$ Int. Conf. Neural Net. Soft Comput., (Zakopane, Poland, 250, 2003)

11. J. Pietraszek, A. Gądek-Moszczak, T. Torunski, Adv. Mat. Res.-Switz., 874, 139 (2014)

12. J. Pietraszek, E. Skrzypczak-Pietraszek, Adv. Mat. Res.-Switz., 874, 151 (2014)

13. J. Pietraszek, A. Goroshko, Adv. Mat. Res.-Switz., 874, 145 (2014)

14. J. Pietraszek, N. Radek, K. Bartkowiak, Solid State Phenom., 197, 198 (2013)

15. T. Pieczonka, J. Kazior, A. Tiziani, A. Molinari, J. Mater. Process. Technol., 64, 327 (1997)

16. M. Ulewicz, U. Lesinska, M. Bochenska, Physicochem. Probl. Mi., 44, 245 (2010)

17. M. Ulewicz, E. Radzyminska-Lenarcik, Physicochem. Probl. Mi., 46, 119 (2011)

18. T. Pieczonka, J. Kazior, A. Szewczyk-Nykiel, M. Hebda, M. Nykiel, Powder Metall., 55, 354 (2012)

19. R. Ulewicz, P. Szataniak, F. Novy, Proc. 23rd International Conference on Metallurgy and Materials (Brno, Czech Republic, 784, 2014)

20. P. Szataniak, F. Novy, R. Ulewicz, Proc. 23rd International Conference on Metallurgy and Materials (Brno, Czech Republic, 778, 2014)

21. T. Lipinski, A. Wach, Proc. 23rd International Conference on Metallurgy and Materials (Brno, Czech Republic, 738, 2014)

22. D. Klimecka-Tatar, S. Borkowski, P. Sygut, Arch. Metall. Mater., 60, 735 (2015)

23. D. Klimecka-Tatar, G. Pawlowska, M. Sozanska, Arch. Metall. Mater., 60, 153 (2015)

24. R. Ulewicz, F.R. Novy, J. Balk. Tribol. Assoc., 22, 1147 (2016)

25. J. Korzekwa, A. Gadek-Moszczak, M. Bara, Prakt. Metallogr.-Pract. Metallogr., 53, 36 (2016) 
26. R. Dwornicka, N. Radek, M. Krawczyk, P. Osocha, J. Pobedza, Proc. $26^{\text {th }}$ Int. Conf. on Metall. and Mater. - METAL (Brno, Czech Republic, 1252, 2017)

27. A. Gadek-Moszczak, Image Anal. Stereol., 36, 151 (2017)

28. A. Gadek-Moszczak, P. Matusiewicz, Image Anal. Stereol., 36, 207 (2017)

29. E. Skrzypczak-Pietraszek, J. Pietraszek, Acta Biol. Crac. Ser. Bot., 51, 62 (2009)

30. E. Skrzypczak-Pietraszek, I. Kwiecien, A. Goldyn, J. Pietraszek, Phytochem. Lett., 20, 443 (2017)

31. A. Gadek-Moszczak, J. Pietraszek, B. Jasiewicz, S. Sikorska, L. Wojnar, Proc. 6th Int. Conf. on Comp. Collective Intell. (ICCCI, Seoul, South Korea, 127-136, 2014)

32. R. Ulewicz, Proc. Int. Conf. Path Forward for Wood Products: A Global Perspective (Baton Rouge, LA, 51, 2016)

33. A. Pacana, R. Ulewicz, Polish J. Environ. Studies, 16, 165 (2017)

34. Kozien, E., Kozien, A., Proc. 23th Int. Sci. Conf. on Economic and Social Dev. (ESD) (Madrid, Spain, 38, 2017)

35. E. Kozień, Proc. $31^{\text {st }}$ Int. Sci. Conf. on Economic and Social Dev. - Legal Challenges of Modern World (ESD) (Split, Croatia, 152, 2018) 